\title{
A RARE CASE OF INGUINAL HERNIA WITH MULLERIAN AGENESIS
}

\author{
K. Veera Venkata Satyanarayana ${ }^{1}$, S. Venkata Reddy², N. S. Ayyappa Morla ${ }^{3}$
}

\section{HOW TO CITE THIS ARTICLE:}

K. Veera Venkata Satyanarayana, S. Venkata Reddy, N. S. Ayyappa Morla. "A Rare Case of Inguinal Hernia with Mullerian Agenesis". Journal of Evolution of Medical and Dental Sciences 2015; Vol. 4, Issue 39, May 14;

Page: 6883-6885, DOI: $10.14260 /$ jemds/2015/997

ABSTRACT: Inguinal hernia with uncommon contents in the hernia sac has been reported in the literature. When ovarian and fallopian tube are found as contents of inguinal hernias, they are commonly associated with defects in genital tract development. We report a case of primary amenorrhea, mullerian agenesis, and an inguinal hernia consisting of an ovary and a fallopian tube. The diagnosis and repair in this case is done by laparoscopy.

KEYWORDS: Inguinal hernia, Mullerian agenesis.

INTRODUCTION: Inguinal hernia containing an ovary and fallopian tube is an extremely rare occurrence. This is commonly associated with defect in genital tract development. Mullerian agenesis is the second most common condition usually diagnosed during work up for primary amenorrhea. The patients with mullerian duct abnormalities have vaginal and uterine hypoplasia with female chromosome pattern (46, XX) and normally functioning ovaries.

CASE REPORT: A twenty years old female presented with complaints of mass in the right inguinal region and primary amenorrhoea. No previous surgeries and no similar complaints in the family. She was a non-smoker and had no history of alcohol or any drug in take. Physical examination revealed no skeletal abnormalities. A reducible mass on palpation, with cough impulse with mild tenderness is present in the left inguinal region. There were no features of hirsutism. Bilateral breasts were well developed and axillary, pubic hair were present. The external genitalia were well developed. No clitoromegaly was found. The blood parameters were in the normal range. On Ultrasound examination no uterus was found, right ovary was normal and left ovary was found in the inguinal canal herniating through deep ring. Laparoscopic exploration was planned. Hernial sac was dissected and reduced along with left ovary and fallopian tube [Figure1a, 1b], uterus is not found and right ovary was normal. Laparoscopic mesh repair of hernial defect was performed [Figure2]. Postoperative recovery is uneventful and evaluation revealed a normal karyotype [46XX].

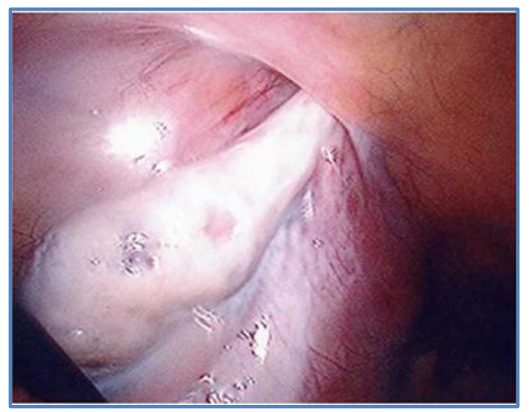

\section{Fig. 1a: Laparoscopic view showing inguinal hernia with herniation of ovary at deep inguinal ring.}




\section{CASE REPORT}

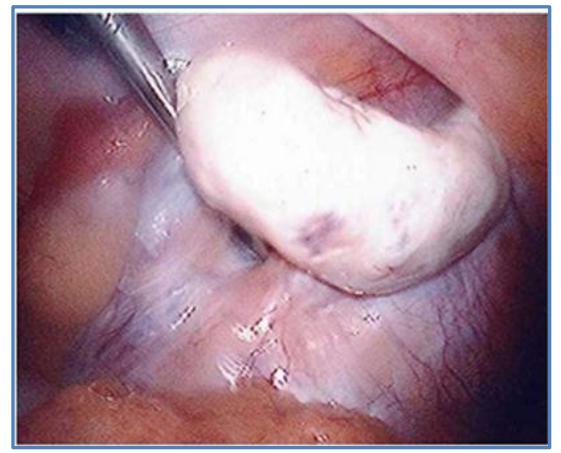

Fig. 1b: Laparoscopic view showing normal appearance of ovary

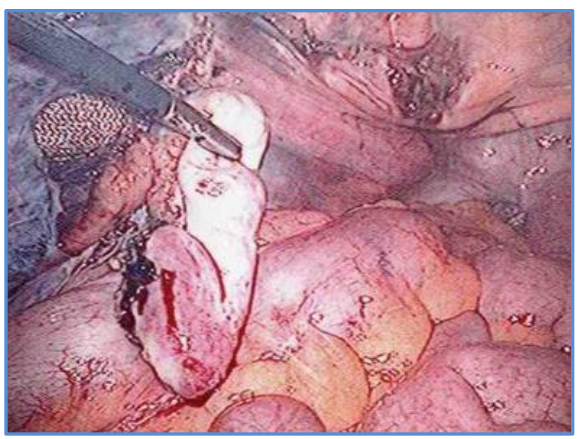

Fig. 2: Laparoscopic view showing hernia sac

dissection with reduction of ovary and mesh repair

DISCUSSION: Mullerian agenesis with ovarian inguinal hernia is a rare entity.[1] The true prevalence of this type of disorder in the reproductive age group is not known. The diagnosis is mostly made either as a part of investigation for primary amenorrhoea or the patient may present as inguinal hernia.

If the ovary gets incarcerated then it becomes an emergency and needs urgent surgery. Marionkovic et al. had reported a case of prolapse irreducible ovary and had recommended urgent operative repositioning of ovary [2] but Vaughn et al. had suggested laparoscopic approach to this inguinal hernia. ${ }^{[3]}$

The migration of gonads is controlled by multiple factors both anatomical and hormonal, which should occur in appropriate time and correct sequence. The presence of ovaries in the inguinal hernia was previously thought to be prolapse but now is assumed as descended gonads like testes.[4]

The Mayer-Rokitansky-Kuster-Hauser (MRKH) syndrome is characterized by congenital aplasia of the uterus and the upper 2/3rdpartof the vagina in women showing normal development of secondary sexual characteristics and a normal 46, XX karyotype.[5,6] Type I MRKH syndrome is characterized by an isolated absence of the proximal two thirds of the vagina, whereas type II is marked by other malformations, including vertebral, cardiac, urologic (Upper tract), and otologic anomalies. 
The first clinical finding is generally a primary amenorrhea in patients presenting with a normal female phenotype, normal 46, XX karyotype, and normal and functioning ovaries without sign of androgen excess. External examination reveals completed puberty with normal secondary female sexual characteristics (Pubic hair and breast development are Tanner stage 5) and normal external genitalia.

CONCLUSION: Laparoscopic approach of inguinal hernias can be an option for surgical repair in patients with müllerian agenesis even when the hernias contain ovaries.

\section{REFERENCES:}

1. Bazi T, Berjawi G, Seoud M. Inguinal ovaries associated with Mullerian agenesis: case report and review. Fertil Steril. 2006; 85(5): 1510.

2. Marinkovic S, Kantardzic M, Bukarica S, Grebeldinger S, Pajic M. When to operate non-reducible ovary? Med Pregl. 1998; 51(11- 12): 537-40.

3. Vaughn TC, Jones HC. Laparoscopic repair of bilateral inguinal hernias in a patient with Mullerian agenesis. Fertil Steril. 2000; 73: 1238.

4. Ozbey H, Ratschek M, Schimpl G, Hollwarth ME. Ovary in hernia sac: prolapsed or descended gonad? J Pediatr Surg. 1999; 34(6): 977-80.

5. Griffin JE, Edward C, Maddan JD. Harrod MJ, Wilsen JD. Congenital absence of the vagina: The Mayer-RokitanskyKusterHauser syndrome. Ann Int Med 1976; 85: 224.

6. Ludwig KS. The Mayer-Rokitansky-Kuster syndrome. An analysis of its morphology and embryology. Part I: Morphology. Arch GynecolObstet 1998; 262: 1-26.

\section{AUTHORS:}

1. K. Veera Venkata Satyanarayana

2. S. Venkata Reddy

3. N. S. Ayyappa Morla

\section{PARTICULARS OF CONTRIBUTORS:}

1. Assistant Professor, Department of General Surgery, Rangaraya Medical College, Kakinada.

2. Associate Professor, Department of General Surgery, Rangaraya Medical College, Kakinada.

3. Senior Resident, Department of General Surgery, Rangaraya Medical College, Kakinada.

FINANCIAL OR OTHER COMPETING INTERESTS: None
NAME ADDRESS EMAIL ID OF THE CORRESPONDING AUTHOR:

K. Veera Venkata Satyanarayana,

Flat 503, Hamsini Arcade, \# 70-7-60/1A, Krishna Nagar,

Ramanayyapeta,

Kakinada-533005,

Andhra Pradesh.

E-mail: satya.medi007@gmail.com

Date of Submission: 21/04/2015.

Date of Peer Review: 22/04/2015.

Date of Acceptance: 06/05/2015.

Date of Publishing: 14/05/2015. 